\title{
Disability Inclusive Employment and the Accommodation Principle: Emerging Issues in Research, Policy, and Law
}

\author{
Peter Blanck ${ }^{1}$ \\ Accepted: 23 October 2020 / Published online: 7 November 2020 \\ (c) Springer Science+Business Media, LLC, part of Springer Nature 2020
}

Keywords People with disabilities · Discrimination · Workplace · Right to employment · Employment insecurity

\section{Disability Inclusive Employment and the Accommodation Principle for People with Disabilities}

At the heart of disability antidiscrimination laws, such as the Americans with Disabilities Act ("ADA") of 1990, the United Nations Convention on the Rights of Persons with Disabilities ("CRPD"), and the laws of other countries, lies the requirement that social institutions affirmatively remove attitudinal and structural barriers confronting people with disabilities as they exercise their rights to particulate fully in society [1]. In disability employment antidiscrimination law and policy, perhaps the most important driver of the inclusion command is the "accommodation principle," which requires that employers make reasonable adjustments to tasks and places of work to enable full and equal participation by qualified individuals with disabilities [2].

In the seminal 2004 U.S. Supreme Court case Tennessee v. Lane [3], the late Justice Ruth Ginsburg wrote of the centrality of the ADA's accommodation principle:

Including individuals with disabilities among people who count in composing "We the People," Congress understood in shaping the ADA, would sometimes require not blindfolded equality, but responsiveness to difference; not indifference, but accommodation. Central to the Act's primary objective, Congress extended the statute's range to reach all government activities, [], and required ... "reasonable accommodations."

Under the ADA, the word "discriminate" consequently includes failure to make reasonable accommodations to the

Peter Blanck

pblanck@syr.edu

1 Burton Blatt Institute, Syracuse University, 950 Irving Avenue, Suite 446, 13244 Syracuse, NY, USA physical and mental limitations of a qualified individual with a disability, in the absence of an "undue hardship" on the business [1]. Discrimination includes denying opportunities to a job applicant or employee if such denial is based on the need for the entity to make reasonable accommodations to that person's physical or mental conditions [1]. By directing employers to accept responsibility, within reason, for accommodations (up to the undue hardship ceiling), the ADA's Title I sets the ADA apart from other U.S. civil rights legislation.

The importance of the accommodation principle to disability inclusive employment law and policy is manifest [4]. The goal of offering equal employment opportunity to everyone, regardless of disability, is meaningless if the new hire uses a wheelchair and the sole entrance to the workplace is up a flight of stairs. The right to work rings hollow if people who are deaf or hard of hearing, who are blind or have low vision, or who have reading or cognitive disabilities cannot use or access a company's web-based technologies [5]. Opportunity is foreclosed when an employer will not alter work schedules within reason, or bars telework or remote work, without consideration for qualified individuals with episodic or mental health conditions, such as depression and anxiety, that require flexibility [6].

Title I of the ADA defines the accommodation principle to include, within reason, making facilities accessible to and usable by individuals with disabilities, as well as job restructuring, part-time and modified work schedules, remote work and telecommuting, modification of equipment and devices, and other effective means of enabling qualified individuals with disabilities to perform essential functions of their jobs, whether traditional or non-traditional [1]. The ADA gives substantial weight to an employer's definition of "essential" job functions and the extent to which such tasks may be done effectively with accommodation. 
Research shows the low costs and the numerous benefits of the accommodation principle. Most workplace accommodations incur de minimis or near-zero costs [7-10]. Employers in most cases can accommodate people with disabilities with relative ease, formally or informally. Further, there are far-reaching, positive ripple effects from a "culture of accommodation" for all $[11,12]$. At the organizational level, accommodations improve employee productivity, morale, and tenure. If an organization promotes a "culture of inclusion," a climate of flexible and supportive approaches, it furthers effective and innovative accommodations and productive outcomes for all employees and for itself $[9,10$, 13-15], and it enjoys the benefits of attracting and retaining qualified workers [13]. The ripple effect extends even further: promoting economic opportunity for people with disabilities produces a corresponding decrease in their need for federal disability insurance and other governmental support funding, along with a resultant increase in tax revenues.

The research thus suggests the value, to all of society, of documenting, devising, and promoting strategies to increase awareness and implementation of the accommodation principle across organizations of different sizes and types, and across market and labor sectors.

At the thirtieth anniversary of the ADA, the articles in this special topic section consider, variously, the future of disability-inclusive employment in light of how the accommodation principle works in contemporary society, and in light of its historical precedents. The accommodation principle as part of a disability inclusive employment paradigm is a concept of the late twentieth century. It contrasts with earlier vocational rehabilitation programs for people with disabilities, which historically were based on medicalized conceptions of disability $[1,16]$. This "Medical Model" of disability focused on individual deficits, with impairments conceived of as infirmities that precluded participation in the mainstream economy $[17,18]$. It cast people with disabilities in a subordinate role to doctors, rehabilitation professionals, and governmental bureaucrats, each of whom aimed to "help them," when "deserving," adjust to a society structured around the convenience, design, and interests of people without disabilities [17].

In contrast, the modern model is the Social Model of disability, which is sometimes called the Ecological Model, and, in the context of the ADA, the Disability Civil Rights Model. This model, however named, includes the accommodation principle. It has changed society's perspective. It has altered the historical paradigm from a focus on a health status to be cured or rehabilitated, and even pitied, towards acceptance of individual differences as human traits that are accommodated in employment, and generally in society, as a natural part of the human experience.

The Social Model of disability has taken on exceptional importance due to the health and economic emergency arising from the global pandemic $[19,20]$. The pandemic is challenging public and private entities in unprecedented ways to spur both traditional and new forms of employment and economic opportunity for all. But people with disabilities are presently experiencing among the highest rates of job loss, as compared to those without disabilities, from the health and economic emergency [21, 22].

Lest we forget, too, people with disabilities often own or identify with multiple minority identities that are themselves marginalized in our society. People with disabilities, for example, may also be women, people of color, and/or individuals identifying with different sexual orientations and gender identities [23-25]. Disability diversity and inclusion ("D\&I") programs that incorporate the accommodation principle for all identities-what my colleagues call "D\&I+"are crucial to people with disabilities who seek to enter or re-enter the mainstream economy.

\section{Disability Inclusive Employment Policy and Practice-The DIEP RRTC}

The unprecedented health, social, and economic challenges raised by today's pandemic require a retrospective, presentday, and prospective view of U.S. employment policy and practice for individuals with disabilities. Over the next five years, the goal of a new national Rehabilitation Research and Training Center on Disability Inclusive Employment Policy ("DIEP RRTC") will be to design and implement a series of studies that produce new data and evidence to increase employment opportunity for people with disabilities [26].

The new DIEP RRTC is forming significant partnerships and bringing together a consortium of nationally recognized and synergized researchers from multiple disciplines including vocational rehabilitation, disability studies, economics, psychology, social work, law and public policy, business, and health policy. The team is comprised of, and directed by, leading members of the disability community. It is complemented by national associations providing unprecedented reach to targeted audiences for knowledge-dissemination activities.

Among its activities, the DIEP RRTC is undertaking a scientifically rigorous set of randomized control trial and quasi-experimental studies on the employment lifecycle of people with disabilities. These studies examine ways to enhance employment engagement, re-engagement, and new forms of work, as well as job quality and retention. They further examine federal, regional, state, local, and private industry policies and programs to identify critical outcomes and impacts that improve employment entry options, wage and income levels, worker retention, job quality and benefits, career growth and paths to economic stability, employment 
reengagement in the event of job loss, and reduced dependence on Social Security disability benefits.

The Center's objectives are to provide policy makers and employers new evidence-based options for employment policy and practice, vocational rehabilitation programs, and workforce development. It also aims to increase strategies to support job seekers with disabilities, and businesses and human resource professionals, by identifying evidence-based practices that enhance worker retention and the quality of the work experience. At the individual level, activities will provide individuals with disabilities access to new knowledge to explore alternative paths to employment and career advancement.

The DIEP RRTC aims, over the longer-term, to provide evidence to support existing and next-generation research in the area. It will disseminate information widely to target audiences in employment policy briefs, academic articles, and academic presentations. Online and in-person training and technical assistance support will be provided for policymakers, business leaders, and people with disabilities. Online trainings and continuing education for vocational rehabilitation and other workforce development professionals, along with webinars and virtual academies, will bring together key stakeholders for collective learning and action.

\section{Contributions to this Special Topic Section}

This special topic section presents transdisciplinary perspectives from American and comparative research, law, and policy regarding the future of disability inclusive employment and the accommodation principle. The articles consider the "new norms" in employment, particularly as relevant to workplace accommodations, such as flexible work hours and reasonable adjustments to the ways work is performed, with a focus on enabling productive participation in the economic mainstream during and after the pandemic and across the spectrum of disabilities.

The articles address traditional employer-employee relationships as well as the relationships developed when people with disabilities choose to create and manage flexible work arrangements that they own and operate, as self- and independent contractors do. The flexibility of such arrangements is one reason that a relatively high proportion of people with disabilities engage in self-employment and independent contracting relationships in the new "gig" economy rather than pursuing (or continuing to pursue) traditional employment $[27,28]$.

In the first article, Schur, Ameri, and Kruse consider that, although the pandemic is a harsh blow to all workers, it may have benefits for some workers with disabilities by making work at home more acceptable and productive [29]. They examine the effects of the pandemic on traditional workplace structures, which have caused employers to rethink how essential tasks can be done, and which may broaden their acceptance of the accommodation principle. Schur and colleagues analyze pre-COVID data on disability and homebased work from national surveys and find that workers with disabilities are more likely than those without disabilities to work primarily or partially at home.

Nonetheless, Schur and colleagues find that workers with disabilities face troubling wage gaps between on-site and home-based work, suggesting that although the "new norm" of home-based work may improve employment opportunities for some workers with disabilities, it may not mitigate their wage disparities. The authors raise important questions for future analysis, such as whether the types of jobs people with disabilities will hold will constrain their potential for economic advancement. While not ignoring the cataclysmic loss of millions of jobs in the current crisis, which is affecting people with disabilities especially negatively, future analysts will need to consider the ways in which the structure of work and employers' views of the accommodation principle may change when the crisis is past and the economy recovers.

Harpur and Blanck next examine people with disabilities as self-employed "gig" workers [30]. Gig work is typically performed independently and outside of the traditional employment relationship historically overseen by regulatory and governmental requirements. Self-directed gig work is scheduled around and compensated by the completion of designated tasks usually organized by an online platform. Because they are acting as independent contractors, gig workers are not afforded the traditional and typical terms, privileges, and benefits associated with "employee" status.

Extending the inquiry by Schur and her colleagues, Harpur and Blanck consider ways in which gig work offers new prospects for income to people with disabilities. They also examine the challenges confronting gig workers with disabilities who engage in this evolving and relatively unregulated sector. They consider regulatory reforms that might be applied to gig work in the U.S. and other countries, offering proposals for improvement in light of the health and economic emergency.

Blanck, Hyseni, \& Altunkol Wise then present firstof-their-kind empirical findings from the first phase of a national longitudinal study on diversity and inclusion in the legal profession, conducted in collaboration with the American Bar Association ("ABA") [21]. Blanck and colleagues build upon and extend prior studies of $D \& I$ in the workplace by proposing that the accommodation principle be added to its conception, resulting in a "D\&I+"-D\&I plus accommodation-model.

With representation from all fifty U.S. states, as well as the District of Columbia, the study's first phase examined 3,590 lawyers with multiple diverse backgrounds. Its 
principal focus was on lawyers who identify as having health conditions, impairments, and disabilities, and on lawyers who identify as lesbian, gay, bisexual, transgender, queer, or as having other sexual orientations and gender identities ("LGBTQ+" as an overarching term) [22, 31].

Although a number of prior efforts in the legal profession have focused on D\&I, these studies have largely examined visible social identities, such as race, ethnicity, gender, age, and others that are readily apparent. Relatively less information is available on the experiences of the people with mixed-visible and nonvisible multiple identities such as having a disability and identifying as LGBTQ+. The study presented here includes findings as to perceptions of, and experiences with, the accommodation principle-workplace accommodations to the nature of work, and associated individual and organizational characteristics.

Preliminary findings suggest that the intersectional experiences of these individuals are complex and merit enhanced additional attention. Current D\&I concepts may be too narrow to adequately address these complexities. Blanck and colleagues propose ways to enhance D\&I outcomes in the legal profession, including the expansion of its traditional conception to $\mathrm{D} \& \mathrm{I}+$, and positioning the accommodation principle as central to enhancing acceptance and maximization of diverse individual talents.

In the last article, examining notions from well before the modern Social Model of disability and its embedded accommodation principle, Logue and Blanck consider the impact on veteran employment of the U.S. government's pension benefit provisions for Union soldiers following the Civil War [16, 24]. They draw on Union army pension records and census returns as well as information derived from the Union army samples as designed by the Center for Population Economics.

Although twentieth-century Progressive reformers contended otherwise, Logue and Blanck find that these nineteenth-century Americans with disabilities wanted what their twenty-first-century counterparts want-work at a meaningful occupation. But the findings also evidence the complex impact on occupational rehabilitation and employment resulting from the public-private partnerships established for Union army veterans. These partnerships were based on different notions of disability needs and rights than those underlying the ADA and its accommodation principle.

Employment was not only this prior era's measure of a meaningful life, but it was also bound up with conceptions of manhood and independence. "Accommodation" was as yet unconceived as a way to enable qualified individuals with disabilities to participate in work. But these post-Civil War experiences did inspire early twentieth-century rehabilitation campaigns as a response to rising industrial accidents and to the carnage of the First World War [32, 23].

\section{Conclusion}

There is a robust literature on disability inclusive employment policy and practice for people with disabilities. The new national DIEP RRTC introduced here aims to contribute to that growing body of study. The centrality of the accommodation principle to this program of study and practice is well-recognized. Although the accommodation principle is of most-obvious import for the traditional employment of people with disabilities, it also must be framed as a principle that should apply for all employment, encouraging the use of universal design approaches, and underlying the approach to non-traditional as well as traditional forms of work $[5,11]$.

Future research by the DIEP RRTC will examine the ways in which organizations of all sizes and types, including those in the gig economy, effectively use the accommodation principle to facilitate the inclusive employment of people with disabilities. In light of the profound changes to employment and society generally brought on by the pandemic, it is crucial to examine ways in which new organizational and individual work strategies evolve, incorporate, and sustain inclusive disability employment policy and practice and the accommodation principle.

The benefits derived from inclusive employment policies and practices may have as-yet untapped positive effects on future participation in the economic mainstream by people with disabilities and others. Improving awareness and use of disability inclusive employment policies and practices, and the accommodation principle, by multiple stakeholders-governmental, organizational, managerial, co-worker, and individual-through a "D\&I+" presentation may further enhance and sustain societal engagement as compared to present approaches [29, 30].

The policy and practice paradigms discussed by the various authors in this special section will, we hope, positively affect organizational culture and individual views and outcomes, all in ways that foster full and equal opportunity for individuals [26]. At the thirtieth anniversary of the ADA, these endeavors are more important than ever, given that, without close attention, the global health and economic emergency may act to limit organizational diversity and inclusion efforts [33]. Disability inclusive employment policy and its accommodation principle are vital to successful and sustained economic activity by people with disabilities in the "new normal" necessitated by the pandemic. And it is worth noting that these approaches may also have positive spillover effects in ways that foster work productivity, tenure, and satisfaction more generally [29, 30].

I conclude as I began, with the important view of Supreme Court Justice Ginsburg: the ADA's 
accommodation principle reflects Congress's finding that "in diverse parts of our Nation ... people with disabilities encounter access barriers... . [This conclusion] warrant[s] the barrier-lowering, dignity-respecting national solution the People's representatives in Congress elected to order" [3].

Acknowledgements I thank Mary Trevor for her comments on a prior version of this article. This special topic section of the Journal of Occupational Rehabilitation is dedicated to the memory of Dr. Helen Schartz, who with grace and great insight significantly advanced research on workplace accommodations.

Funding This line of study was supported in part by grants to Syracuse University, Peter Blanck (Principal Investigator) from the National Institute on Disability, Independent Living, and Rehabilitation Research (NIDILRR) for the Rehabilitation Research \& Training on Employment Policy: Center for Disability-Inclusive Employment Policy Research Grant \#90RTEM0006-01-00, and the Southeast ADA Center, Grant \#90DP0090-01-00. NIDILRR is a Center within the Administration for Community Living (ACL), Department of Health and Human Services (HHS). The views provided herein do not necessarily reflect the official policies of NIDILRR nor do they imply endorsement by the Federal Government.

\section{Compliance with Ethical Standards}

Conflict of interest Author Peter Blanck declares that he has no conflict of interest.

\section{References}

1. Blanck P. Disability Law and Policy. St. Paul: Foundation Press; 2020.

2. Blanck P. Why America is better off because of the Americans with Disabilities Act and the Individuals with Disabilities Education Act. Touro Law Rev. 2019;35:605-618.

3. Tennessee v. Lane, 541 U.S. 509 (2004).

4. Ali M, Schur L, Blanck P. What types of jobs do people with disabilities want? J Occup Rehabil. 2011;21(2):199-210.

5. Blanck P, eQuality. The struggle for web accessibility by persons with cognitive disabilities. NY: Cambridge University Press; 2014.

6. Blanck P. The First "A" in the ADA: and 25 more "A"s toward equality for Americans with Disabilities. Inclusion. 2016;4(1):46-51.

7. Schur L, Nishii L, Adya M, Kruse D, Bruyère SM, Blanck P. Accommodating employees with and without disabilities. Hum Resour Manag. 2014;53(4):593-621.

8. Blanck P. The economics of the employment provisions of the Americans with Disabilities Act: Part I-Workplace Accommodations. DePaul Law Rev. 1997;46(4):877-914.

9. Schartz H, Schartz K, Hendricks DJ, Blanck P. Workplace accommodations: empirical study of current employees. Miss Law J. 2006;75:917-43.

10. Schartz H, Hendricks DJ, Blanck P. Workplace accommodations: evidence-based outcomes. Work. 2006;27:345-354.

11. Stein M, Silvers A, Areheart BA, Francis L. Accommodating every body. Univ Chic Law Rev. 2014;81(2):689-756.
12. Schur L, Kruse D, Blasi J, Blanck P. Is disability disabling in all workplaces? Disability, workplace disparities, and corporate culture. Ind Relat. 2009;48(3):381-410.

13. Maestas N, Mullen KJ, Rennane S. Unmet need for workplace accommodation. J Policy Anal Manag. 2019;38(4):1004-1027.

14. Stone D, Colella A. A model of factors affecting the treatment of disabled individuals in organizations. Acad Manag Rev. 1996;21(2):352-401.

15. Zwerling C, Whitten PS, Sprince NL, Davis CS, Wallace RB, Blanck P, et al. Workplace accommodations for people with disabilities: national health interview survey disability supplement, 1994-1995. J Occup Environ Med. 2003;45(5):517-525.

16. Logue L, Blanck P. Before the accommodation principle: disability and employment among Union Army veterans. J Occup Rehabil. 2020 (this issue).

17. Blanck P, Millender M. Before civil rights: Civil War pensions and the politics of disability in America. Ala Law Rev. 2000;52:1-50.

18. Blanck P. Civil War pensions and disability. Ohio State Law J. 2001;62:109-249.

19. Shogren K, Wehmeyer M, Martinis J, Blanck P. Supported decision-making: theory, research, and practice to enhance selfdetermination and quality of life. NY: Cambridge University Press; 2019.

20. Blanck P. Supported decision-making: emerging paradigm in research, law, and policy. J Disabil Policy Stud. 2020; (in press).

21. Blanck P, Hyseni F, Altunkol Wise F. Diversity and inclusion in the American legal profession: workplace accommodations for lawyers with disabilities and lawyers who identify as LGBTQ+. J Occup Rehabil. 2020 (this issue).

22. Blanck P, Abdul-Malak Y, Adya M, Hyseni F, Killeen M, Altunkol Wise F. Diversity and inclusion in the American legal profession: First phase findings from a national study of lawyers with disabilities and lawyers who identify as LGBTQ+. Univ DC Law Rev. 2020;23:23-87.

23. Logue L, Blanck P. Race, ethnicity, and disability: veterans and benefits in Post-Civil War America. NY: Cambridge University Press; 2010.

24. Logue L, Blanck P. "Benefit of the doubt": African-American Civil War veterans and pensions. J Interdiscip Hist. 2008;xxxviii(3):377-399.

25. Blanck P. Americans with Disabilities Act at thirty: disability law and policy in 2020. J Disabil Policy Stud. 2020; (in press).

26. Blanck P. [Principal investigator]. Rehabilitation Research Training Center on Employment Policy, funded by the U.S. National Institute on Disability, Independent Living, and Rehabilitation Research (NIDILRR). 2020.

27. Ostrow L, Smith C, Nemec PB. Self-employment for people with psychiatric disabilities: advantages and strategies. J Behav Health Serv Res. 2019;46:686-696.

28. Ostrow L, Smith C, Penney D, Shumway M. "It suits my needs": self-employed individuals with psychiatric disabilities and small businesses. Psych Rehab J. 2018;42(2):121-131.

29. Schur L, Ameri M, Kruse D. Telework after COVID: a "silver lining" for workers with disabilities? J Occup Rehabil. 2020 (this issue).

30. Harpur P, Blanck P. Gig workers with disabilities: opportunities, challenges, and regulatory response. J Occup Rehabil. 2020 (this issue).

31. Blanck P, Hyseni F, Altunkol Wise F. Diversity and inclusion in the legal profession: discrimination and bias reported by lawyers with disabilities and lawyers who identify as LGBTQ+. Am J Law Med. 2021;46(4):__-__ (in press). 
32. Logue L, Blanck P. Heavy laden: Union veterans, psychological illness, and suicide. New York: Cambridge University Press; 2018.

33. Morrison C. Don't let the shift to remote work sabotage your inclusion initiatives. In The i4cp Productivity Blog. 2020. https ://www.i4cp.com/coronavirus/dont-let-the-shift-to-remote-worksabotage-your-inclusion-initiatives?referringSource $=$ articleShare. Accessed 14 Oct. 2020.
Publisher's Note Springer Nature remains neutral with regard to jurisdictional claims in published maps and institutional affiliations. 